\title{
Microhardness of Ceramics Obtained by Different Methods from Nanopowders of Different Oxides
}

\author{
By Vladimir Lysenko* \\ Vyacheslav Mali \\ Alexander Anisimov ${ }^{*}$
}

\begin{abstract}
The method of spark plasma sintering (SPS) is used for the creation of fine-grained ceramics on the basis of various nanodimensional powders of alumina and other oxides. A comparison of the microhardness of ceramic samples obtained from 11 alumina nanopowders and 2 of their composites was held. The microhardness of ceramics obtained both by SPS, and by the traditional method (at successive pressing and sintering) is compared. The dependence of ceramics microhardness on the phase composition of the initial nanopowder and the average size of its particles were investigated. Besides alumina (Al2O3) nanopowders, a comparison was made of the microhardness of ceramics from nanopowders of 13 other oxides ( $\mathrm{SiO} 2, \mathrm{ZnO}, \mathrm{Fe} 3 \mathrm{O} 4, \mathrm{CuO}, \mathrm{Cr} 2 \mathrm{O} 3, \mathrm{Gd} 2 \mathrm{O} 3, \mathrm{CoO}, \mathrm{WO} 3, \mathrm{MgO}$, $\mathrm{Nb2O5}$, TiO2, Y2O3, ZrO2) obtained both by SPS, and by the traditional method. It is found that the microhardness of the ceramics created by the method of spark plasma sintering, is significantly higher than the microhardness of the ceramics obtained by the traditional method; at the SPS method the average size of ceramics grains decreases (to 1 micron and less).
\end{abstract}

\section{Introduction}

The existence of nanoparticles in the structure of materials adds to the materials' new properties. The electronic structure, conductivity, reactionary ability, temperature of melting and mechanical characteristics change. Nanotechnologies can lead to the creation of stronger and easier constructional materials, superhard and wear-resistant coverings to increase the capacity of magnetic medium, etc.

Differences between nanocrystal and coarse-grained materials in elastic, damping, strength, thermal, electric, magnetic and diffusive properties are caused not only by the small size of grains in nanocrystal materials, but also by

${ }^{*}$ Leading Scientist, Russian Academy of Sciences, Russia.

${ }^{\dagger}$ Leading Scientist, Russian Academy of Sciences, Russia.

${ }^{\star}$ Senior Scientist, Russian Academy of Sciences, Russia. 
a special condition of a surface or borders of grains in them (Moiseev, et al., 2003).

One of the directions of nanotechnologies is the creation of the ceramics obtained from nanodimensional powders, in which it is possible to keep very small grain sizes. It is supposed that the nanoceramics will possess not only properties of the ceramics obtained from coarse-grained materials, - the high strength, resistance to influence of high temperatures and corrosion, high isolating characteristics, - but also some unique characteristics (for example, superplasticity (Zhou Xinzhang, et al., 2005). The current state of researches on nanoceramics is rather well displayed in (Physicochemistry, 2000; Nanoparticles, 2004; Nanostructures, 2007), etc.

It is known that the smaller the size of ceramics grains, and the more the granular structure is developed, the stronger and harder the ceramics are.

At the same time in the nanopowders used for obtaining ceramics, there are steady hardly-destroyed agglomerates of nanoparticles (Antsiferov \& Perelman, 2001; Bae, et al., 2002) that demand application of non-standard methods of compaction (for example, a method of the hot pressing).

The creation - by means of the SPS method from nanodisperse alumina powders (of different types) and from nanodisperse powders of different oxides - of the dense and hard ceramics with fine-grained (about 1 micron) structure and also the comparison of microhardness of the ceramics samples obtained by two different methods (spark plasma sintering and traditional method) was the purpose of this work.

\section{Description of Experimental Conditions}

Various nanopowders of alumina $\mathrm{Al}_{2} \mathrm{O}_{3}$ (of chemical purity of 99-99.9\%) were obtained on different facilities and different methods were applied to ceramics creation. In these researches the nanopowders of two Russian companies - "Plasmotherm" (here powders are synthesized in a stream of the thermal plasma generated in an electric discharge) and "Novosibirsk nanomaterials" (NskNano) (here the electric conductor explosion is applied) were used. For these powders the sintering was carried out on the Labox "Sinter Land" facility of the Institute of Hydrodynamics of the Siberian Branch of the Russian Academy of Science (SB RAS) by the method of spark plasma sintering (SPS) where impulses of electric current (of $2 \mathrm{kA}$ about) pass through in-advance pressed powder. The main difference between the SPS method and the traditional method (at consecutive pressing and sintering) is the pulse electric current leading directly to a sample that promotes fast powder heating and the substantial preservation of its microstructural parameters in the consolidated material. The pressing was carried out generally at the maximum temperature of $1400^{\circ} \mathrm{C}$ (in additional experiments at 1200 and $1600^{\circ} \mathrm{C}$ ) and pressure of $40 \mathrm{MPa}$. The speed of heating was $100^{\circ} / \mathrm{min}$, the soaking at the maximum temperature wasn't. The diameter of the obtained samples was 10 $\mathrm{mm}$, the thickness $-2.6-3.0 \mathrm{~mm}$. The ceramics density was $3.7-3.95 \mathrm{~g} / \mathrm{cm}^{3}$. 
Also the ceramics obtained from nanopowders (of chemical purity of 9999.9\%) of oxides of: titanium, zirconium, copper, tungsten, zinc, chromium, cobalt, niobium and magnesium (created by the Russian company "Plasmotherm"), and also of oxides of silicon, iron, gadolinium and yttrium, were investigated. For these powders, the sintering was carried out on the same Labox "Sinter Land" facility. Pressing was carried out at different maximum temperatures (from 600 to $1600^{\circ} \mathrm{C}$ ) and pressure of $40 \mathrm{MPa}$. The diameter of samples was $10 \mathrm{~mm}$, the thickness $-1.2-3.2 \mathrm{~mm}$.

The maximum microhardness of the ceramics samples obtained by the SPS method was compared to the maximum microhardness of the ceramics described in works by Bardakhanov, et al. (2008-2010) and synthesized by the traditional method from nanopowders of various companies: $\mathrm{Al}_{2} \mathrm{O}_{3}$ (Siberian Chemical Plant, Degussa (Evonik Industries AG, Germany), ITAM-INPh of the Siberian Branch of the Russian Academy of Science, Sumitomo Chemical (Japan)), $\mathrm{TiO}_{2}, \mathrm{CuO}, \mathrm{WO}_{3}, \mathrm{ZnO}, \mathrm{Y}_{2} \mathrm{O}_{3}$ (ITAM-INPh of the SB RAS), $\mathrm{ZrO}_{2}$ (Siberian Chemical Plant).

The microhardness of all ceramics samples was investigated by means of the microhardness gage PMT-3.

\section{Results}

The obtained results of the microhardness research of ceramics samples from various alumina nanopowders are given in Fig. 1. The average particles size $d$ and phase structure for each powder (No - its number) is specified in the caption to this Figure.

Note that the ceramics at No. 4 and 7 were fragile, not crack-resisting.

According to phase structure, the powders by vertical lines in the Figure are divided into 4 zones: (1) $\delta$ - and $\theta$-phases, (2) $\gamma$-phase, (3) $\alpha$-phase (corundum), (4) composites on the basis of the $\mathrm{Al}_{2} \mathrm{O}_{3}$ powders of $\alpha$-phase.

From the Figure, three clear conclusions follow:

1. The microhardness of the ceramics obtained by the method of the spark plasma sintering (SPS) is significantly higher than the microhardness of the ceramics obtained by the traditional method.

2. The ceramics microhardness strongly depends on the phase structure of the initial nanopowder. It increases with change of the powder phase structure in such sequence: (1) $\delta$ - and $\theta$-phases, (2) $\gamma$-phase, (3) $\alpha$-phase, (4) composites on the basis of the $\mathrm{Al}_{2} \mathrm{O}_{3}$ powders of $\alpha$-phase.

3 . For the ceramics of $\alpha$-phase (corundum), obtained by the same method (either traditional, or SPS), the ceramics microhardness is higher, than less the average size of the initial-powder particles. 
Figure 1. The microhardness of the ceramics from various alumina $\mathrm{Al}_{2} \mathrm{O}_{3}$ nanopowders

- - the ceramics obtained by the traditional method (at consecutive pressing and sintering) (Bardakhanov, et al., 2009a),

$\boldsymbol{\Delta}$ - the ceramics obtained by the method of spark plasma sintering (SPS).

The used alumina nanopowders:

1 - A (plasmochemical), mix of $\delta$ - and $\theta$-phases, $d=300 \mathrm{~nm}$ (Siberian Chemical Plant)

2- Aluminum Oxide C, $\gamma$-phase, $d=13 \mathrm{~nm}$ (Degussa [Evonik Industries AG], Germany)

3- B, $\gamma$-phase, $d=33 \mathrm{~nm}$ (ITAM-INPh of SB RAS)

4- $\mathrm{Al}_{2} \mathrm{O}_{3}$, mix $\gamma$-(80\%), $\delta$-and $\theta$-phases, $d=25 \mathrm{~nm}$ (NskNano)

5-AM-21, $\alpha$-phase, $d=4000 \mathrm{~nm}$ (Sumitomo Chemical, Japan)

6- $\mathrm{Al}_{2} \mathrm{O}_{3}$, mix of $\alpha$-phase (34\%), $\delta$-phase and $\theta$-phase, $d=80-100 \mathrm{~nm}$ (Plasmotherm)

7- $\mathrm{Al}_{2} \mathrm{O}_{3}$ nanofibres, mix of $\alpha$-phase (95\%) and $\theta$-phase, $d=200-300 \mathrm{~nm}$ (NskNano)

8- $\mathrm{Al}_{2} \mathrm{O}_{3}, \alpha$-phase (95\%), $\theta$-phase (5\%), $d=200-300 \mathrm{~nm}$ (NskNano)

9-AKP-50, $\alpha$-phase, $d=200 \mathrm{~nm}$ (Sumitomo Chemical, Japan)

10-AKP-60, $\alpha$-phase, $d=177 \mathrm{~nm}$ (Sumitomo Chemical, Japan)

11- $\mathrm{Al}_{2} \mathrm{O}_{3}, \alpha$-phase (100\%), $d=185 \mathrm{~nm}$ (Plasmotherm)

12- composite: $\mathrm{Al}_{2} \mathrm{O}_{3}$ ( $\alpha$-phase, $d=185 / 200 \mathrm{~nm}, 98 \%, \boldsymbol{\Delta}$ Plasmotherm, $\bullet A K P$ 50), $\mathrm{MgO}(d=25 / 73 \mathrm{~nm}, 2 \%)$

13- composite: $\mathrm{Al}_{2} \mathrm{O}_{3}$ ( $\alpha$-phase, $d=185 \mathrm{~nm}$, Plasmotherm, 95\%), $\mathrm{MgO}(\mathrm{d}=25$ $\mathrm{nm}, 3 \%), \mathrm{Y}_{2} \mathrm{O}_{3}(d=32 \mathrm{~nm}, 2 \%)$

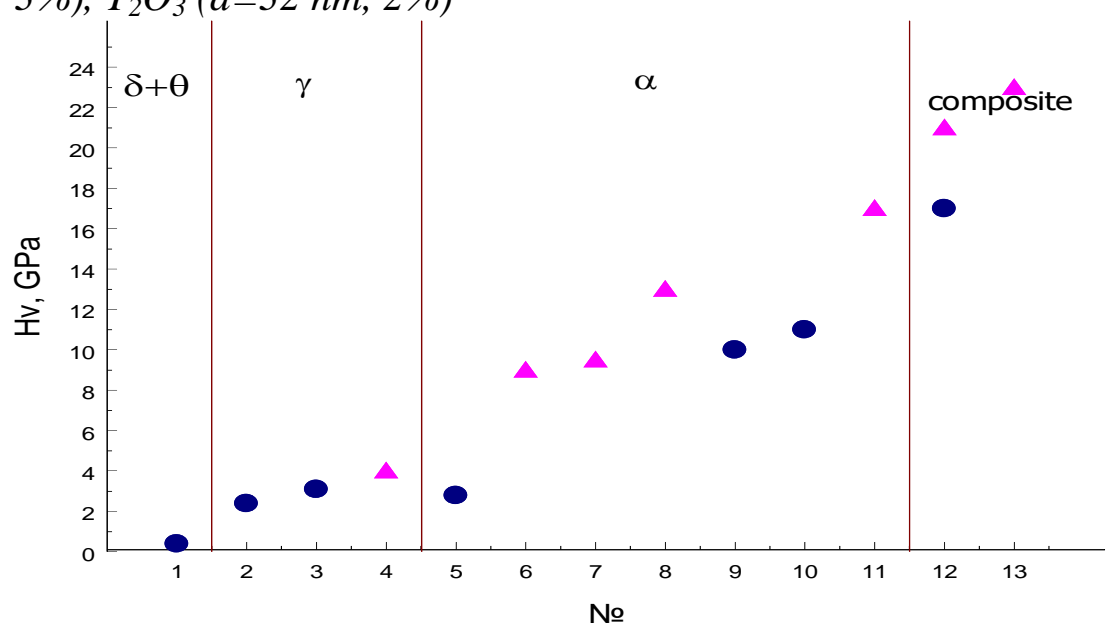


Then by means of an electronic scanning microscope of ZEISS EVO50WDS-XVP-BU, the structure of ceramics obtained by the SPS method was investigated. A comparison was carried out with the data of scanning electronic microscopy for the ceramics obtained by the traditional method (Bardakhanov, et al., 2009a).

Figure 2. The scanning electronic microscopy of a chip of the ceramics prepared by the SPS method: a) from the alumina powder ( $\alpha$-phase, $d=185 \mathrm{~nm}$, Plasmotherm); b) from the components: $\mathrm{Al}_{2} \mathrm{O}_{3}$ ( $\alpha$-phase, $d=185 \mathrm{~nm}, 98 \%$ ), $\mathrm{MgO}(d=25 \mathrm{~nm}, 2 \%), c)$ from the components: $\mathrm{Al}_{2} \mathrm{O}_{3}$ ( $\alpha$-phase, $d=185 \mathrm{~nm}$, $95 \%), \mathrm{MgO}(d=25 \mathrm{~nm}, 3 \%), \mathrm{Y}_{2} \mathrm{O}_{3}(d=32 \mathrm{~nm}, 2 \%)$.

a)

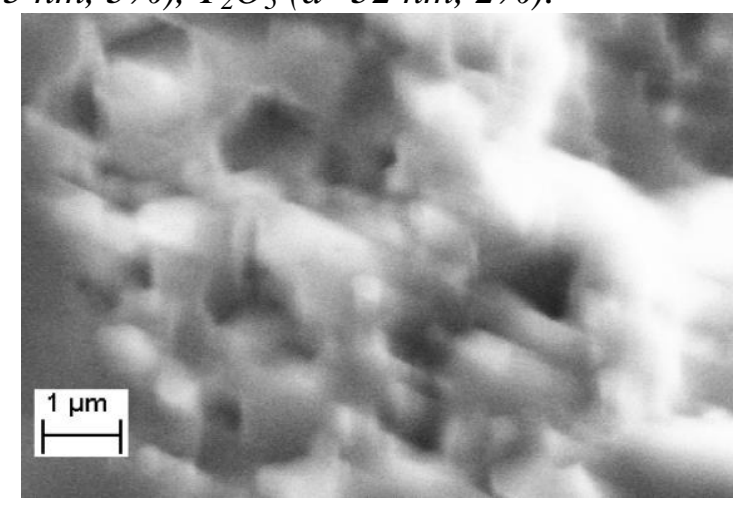

b)
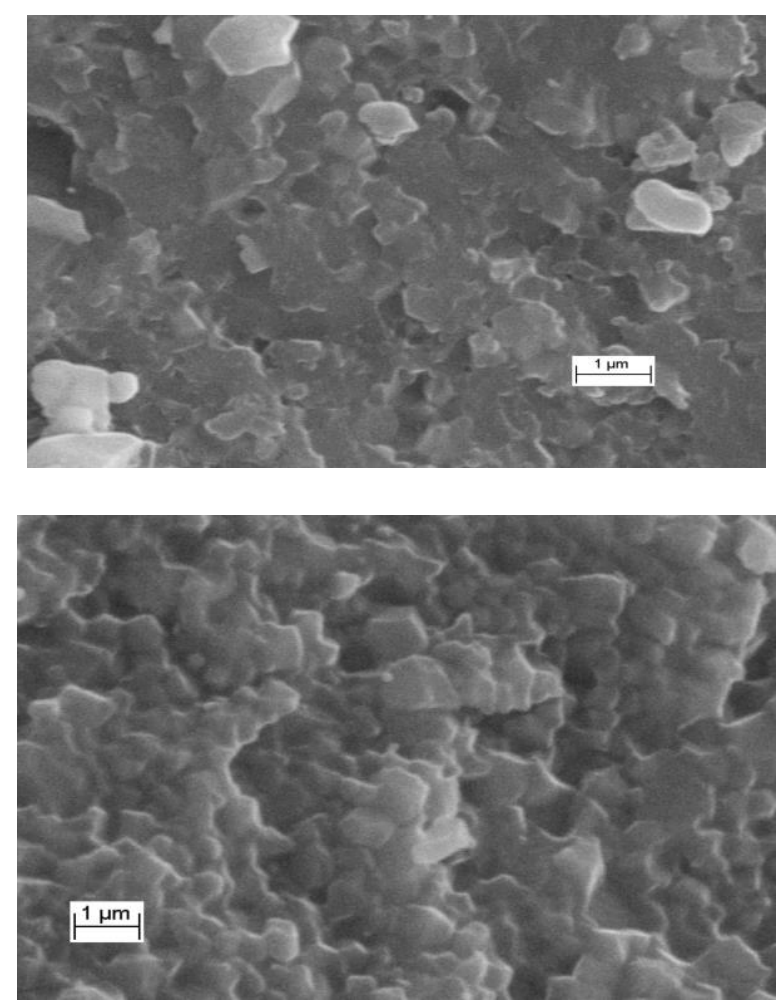

c)

The scanning electronic microscopy of the sample of a chip of the ceramics (of the density of $3.95 \mathrm{~g} / \mathrm{cm}^{3}$ ), created from the $\mathrm{Al}_{2} \mathrm{O}_{3}$ powder $(100 \%$ 
$\alpha$-phase, "Plasmotherm", the average particles size of $185 \mathrm{~nm}$ ) by the SPS method (at $p_{\max }=40 \mathrm{MPa}$ and $\mathrm{T}_{\max }=1400^{\circ} \mathrm{C}$ ) is given in Fig. 2a. It was compared to scanning electronic microscopy of the sample of ceramics (of the density of $3.9 \mathrm{~g} / \mathrm{cm}^{3}$ ), prepared by the traditional method (at $p_{\max }=40 \mathrm{MPa}$ and $\mathrm{T}_{\max }=1500^{\circ} \mathrm{C}$ ) from the alumina AKP-50 powder (the average size of particles of $200 \mathrm{~nm}$ ) (Bardakhanov, et al., 2009a).

It appeared that if the grain size in the ceramics from the AKP-50 is 3-5 microns, the grain size of the ceramics from the $\mathrm{Al}_{2} \mathrm{O}_{3}$ powder ( $\alpha$-phase, "Plasmotherm") - is about 1 micron. Thus the microhardness of the first ceramics was $10 \mathrm{GPa}$, and of the second - $17 \mathrm{GPa}$. These data confirm that the size of ceramics grains is less and the granular structure is more developed; the ceramics are stronger and harder.

The alumina powders were used not only in pure form, but also as a part of compositions.

In Figs. $2 b$ and $2 c$, the pictures are given of scanning electronic microscopy of a chip of the ceramics prepared by the SPS method (at $p_{\max }=40$ $\mathrm{MPa}$ and $\mathrm{T}_{\max }=1400^{\circ} \mathrm{C}$ ) from the components: $\mathrm{Al}_{2} \mathrm{O}_{3}$ ( $\alpha$-phase, $d=185 \mathrm{~nm}$, Plasmotherm, 95\%), $\mathrm{MgO}(d=25 \mathrm{~nm}, 2 \%)$ (Fig. 2b), and $\mathrm{Al}_{2} \mathrm{O}_{3}$ ( $\alpha$-phase, $d=185 \mathrm{~nm}$, Plasmotherm, 95\%), $\mathrm{MgO}(d=25 \mathrm{~nm}, 3 \%), \mathrm{Y}_{2} \mathrm{O}_{3}(d=32 \mathrm{~nm}, 2 \%)$ (Fig. 2c). They were compared to scanning electronic microscopy of the ceramics prepared from the components: $\mathrm{Al}_{2} \mathrm{O}_{3}(200 \mathrm{~nm}, 95 \%), \mathrm{MgO}(73 \mathrm{~nm}$, $2 \%), \mathrm{Al}_{2} \mathrm{O}_{3}(13 \mathrm{~nm}, 3 \%)$ by the traditional way (pressed at $p_{\max }=40 \mathrm{MPa}$ and sintered at $\mathrm{T}_{\max }=1500^{\circ} \mathrm{C}$ ) (Bardakhanov, et al., 2009a).

While the grain size in the composite ceramics on the basis of AKP-50 reaches 3-5 microns, the grain size in the composite ceramics on the basis of $\mathrm{Al}_{2} \mathrm{O}_{3}$ ( $\alpha$-phase, "Plasmotherm") - is about 1 micron. The microhardness of the first ceramics was $16-18 \mathrm{GPa}$, and of the second ceramics - $21 \mathrm{GPa}$ (with use of $\mathrm{Y}_{2} \mathrm{O}_{3}$ additives $-23 \mathrm{GPa}$ ).

According to the radiographic research of phase structure, all three samples of the composite ceramics contained the main phase $\alpha-\mathrm{Al}_{2} \mathrm{O}_{3}$ (corundum of rhombohedral modification), in the form of impurity $-\mathrm{MgAl}_{2} \mathrm{O}_{4}$ spinel (of cubic modification). The generation of spinel, even in a small quantity, promotes the high hardness of ceramics. And with a small additive of the nanopowder $\mathrm{Y}_{2} \mathrm{O}_{3}$ into the initial mixture of the $\mathrm{Al}_{2} \mathrm{O}_{3}$ and $\mathrm{MgO}$ powders at the emergence in obtained ceramics of additional impurity $-\mathrm{Al}_{2} \mathrm{O}_{3}$ of hexagonal modification (the corundum modified by yttrium) (and in the absence of the yttrium aluminum garnet $\mathrm{Y}_{3} \mathrm{Al}_{5} \mathrm{O}_{12}$ microphase) - the hardness of the obtained ceramics increases even more.

Also the ceramics obtained from the nanopowders of oxides of: titanium, zirconium, copper, tungsten, zinc, chromium, cobalt, niobium, magnesium, silicon, iron, gadolinium and yttrium, were investigated.

The obtained data on the microhardness of the ceramics are given in Fig. 3. The average size of particles and the maximum sintering temperature for each powder (No - its number) are specified in the caption to this Figure. 
From Fig. 3 it clearly follows that the microhardness of the ceramics obtained by the SPS method, is significantly higher than the microhardness of the ceramics obtained by the traditional method.

Figure 3. The microhardness of ceramics from various oxides nanopowders.

- - the ceramics obtained by the traditional method (at consecutive pressing and sintering),

- - the ceramics obtained by the method of spark plasma sintering (SPS),

$\square-$ the coarse-grained (d>4-5 micron) ceramics obtained by the traditional method.

The used oxides nanopowders:

1- $\mathrm{SiO}_{2}, d=25 \mathrm{~nm}(\mathrm{ITAM}-\mathrm{INPh}$ of $\mathrm{SB} \mathrm{RAS}), \bullet T_{\max }=1500^{\circ} \mathrm{C}, \boldsymbol{\Delta} \quad T_{\max }=1000^{\circ} \mathrm{C}$ (Anisimov, et al., 2013)

2- $\mathrm{ZnO}, d=70 \mathrm{~nm}$ (Plasmotherm), $T_{\max }=1200^{\circ} \mathrm{C}$

3- $\mathrm{Fe}_{3} \mathrm{O}_{4}, d=18 \mathrm{~nm}$ (ITAM-INPh of SB RAS), $T_{\max }=900^{\circ} \mathrm{C}$ (Lysenko, et al., 2013)

4- $\bullet C u O, d=140 \mathrm{~nm}$ (ITAM-INPh of SB RAS), $T_{\max }=800^{\circ} \mathrm{C}$ (Bardakhanov, et al., 2010)

$\Delta \mathrm{CuO}, d=80 \mathrm{~nm}$ (Plasmotherm), $T_{\max }=900^{\circ} \mathrm{C}$

5- $\mathrm{Cr}_{2} \mathrm{O}_{3}, d=110 \mathrm{~nm}$ (Plasmotherm), $T_{\max }=800^{\circ} \mathrm{C}$

6- $\mathrm{Gd}_{2} \mathrm{O}_{3}, d=54 \mathrm{~nm}$ (ITAM-INPh of $S B \mathrm{RAS}$ ), $T_{\max }=1500^{\circ} \mathrm{C}$, (Bardakhanov, et al., 2008)

7- $\mathrm{CoO}, d=40 \mathrm{~nm}$ (Plasmotherm), $T_{\max }=600^{\circ} \mathrm{C}$

8- $\bullet \mathrm{WO}_{3}, d=140 \mathrm{~nm}$ (ITAM-INPh of SB RAS), $T_{\max }=1100^{\circ} \mathrm{C}$ (Bardakhanov, et al., 2009b)

$\Delta \mathrm{WO}_{3}, d=60 \mathrm{~nm}$ (Plasmotherm), $T_{\max }=800^{\circ} \mathrm{C}$ [

9- $\mathrm{MgO}, d=25 \mathrm{~nm}$ (Plasmotherm), $T_{\max }=1600^{\circ} \mathrm{C}$

$10-\mathrm{Nb}_{2} \mathrm{O}_{5}, d=60 \mathrm{~nm}$ (Plasmotherm), $T_{\max }=800^{\circ} \mathrm{C}$

11- $-\mathrm{TiO}_{2}$ (brookite), $d=78 \mathrm{~nm}$ (ITAM-INPh of SB RAS), $T_{\max }=1600^{\circ} \mathrm{C}$ (Bardakhanov, et al., 2009c)

$\Delta \mathrm{TiO}_{2}$ (anatase/rutile), $d=90 \mathrm{~nm}$ (Plasmotherm), $T_{\max }=1100^{\circ} \mathrm{C}$

12- $\bullet \mathrm{Al}_{2} \mathrm{O}_{3}$ (AKP-50), $d=200 \mathrm{~nm}$ (Sumitomo Chemical, Japan), $T_{\max }=1500^{\circ} \mathrm{C}$ (Bardakhanov, et al., 2009a)

$\triangle \mathrm{Al}_{2} \mathrm{O}_{3}, d=185 \mathrm{~nm}$ (Plasmotherm), $T_{\max }=1400^{\circ} \mathrm{C}$

13- $\mathrm{Y}_{2} \mathrm{O}_{3}, d=32 \mathrm{~nm}\left(\right.$ ITAM-INPh of SB RAS) $\left(\bullet T_{\max }=1500^{\circ} \mathrm{C}\right.$, Bardakhanov, et al., 2008; $\boldsymbol{\Delta}$ this work, $T_{\max }=1400^{\circ} \mathrm{C}$ )

14- $\bullet \mathrm{ZrO}_{2}(91 \%, d=20 \mathrm{~nm})+\mathrm{MgO}(9 \%)$ (Siberian Chemical Plant), $T_{\max }=1500^{\circ} \mathrm{C}$ (Bardakhanov, et al., 2009d)

A $\mathrm{ZrO}_{2}, d=70 \mathrm{~nm}$ (Plasmotherm), $T_{\max }=1500^{\circ} \mathrm{C}$ 


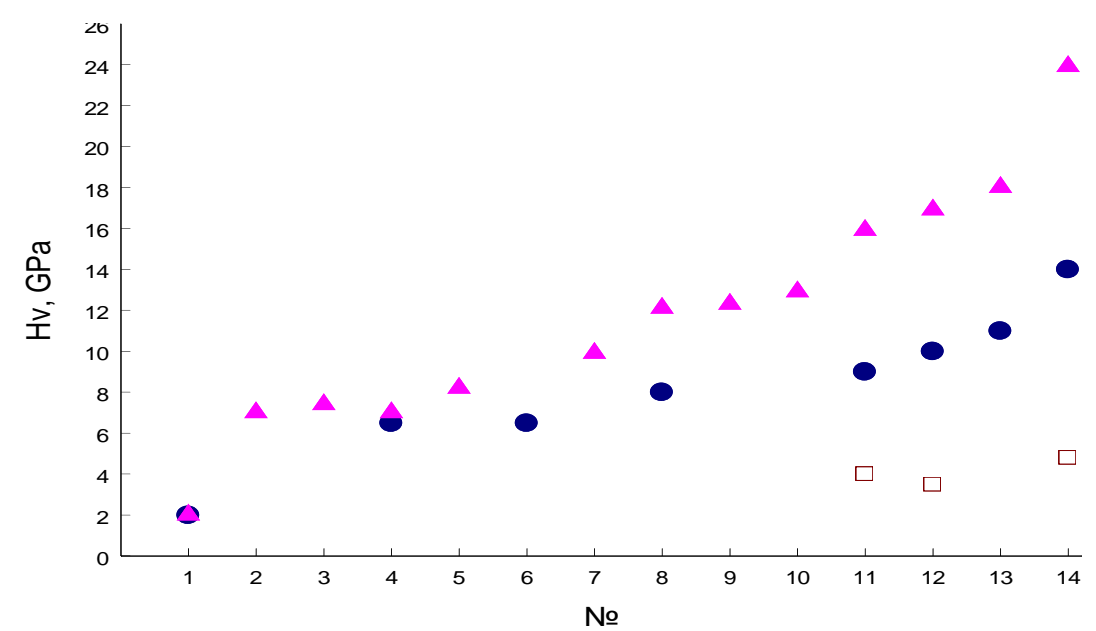

In Fig. $4 \mathrm{a}$, is the picture of scanning electronic microscopy of a chip of the ceramics sample of yttrium oxide $\mathrm{Y}_{2} \mathrm{O}_{3}$ prepared by the SPS method at $\mathrm{T}_{\max }=1500^{\circ} \mathrm{C}$ from the same powder of yttrium oxide as in work by Bardakhanov, et al. (2008), in which the ceramics were created at $\mathrm{T}_{\max }=1500^{\circ} \mathrm{C}$ in the traditional way. According to survey photos of electronic microscopy of the indicated work sample, the estimated average size of grains of yttrium oxide is about 10 microns. As researches of the obtained samples showed, for ceramics from yttrium oxide the microhardness was about $11 \mathrm{GPa}$.

Figure 4. The scanning electronic microscopy of a chip of the ceramics prepared by the SPS method from nanopowders of: (a) yttrium oxide, (b) zinc oxide, (c) silica
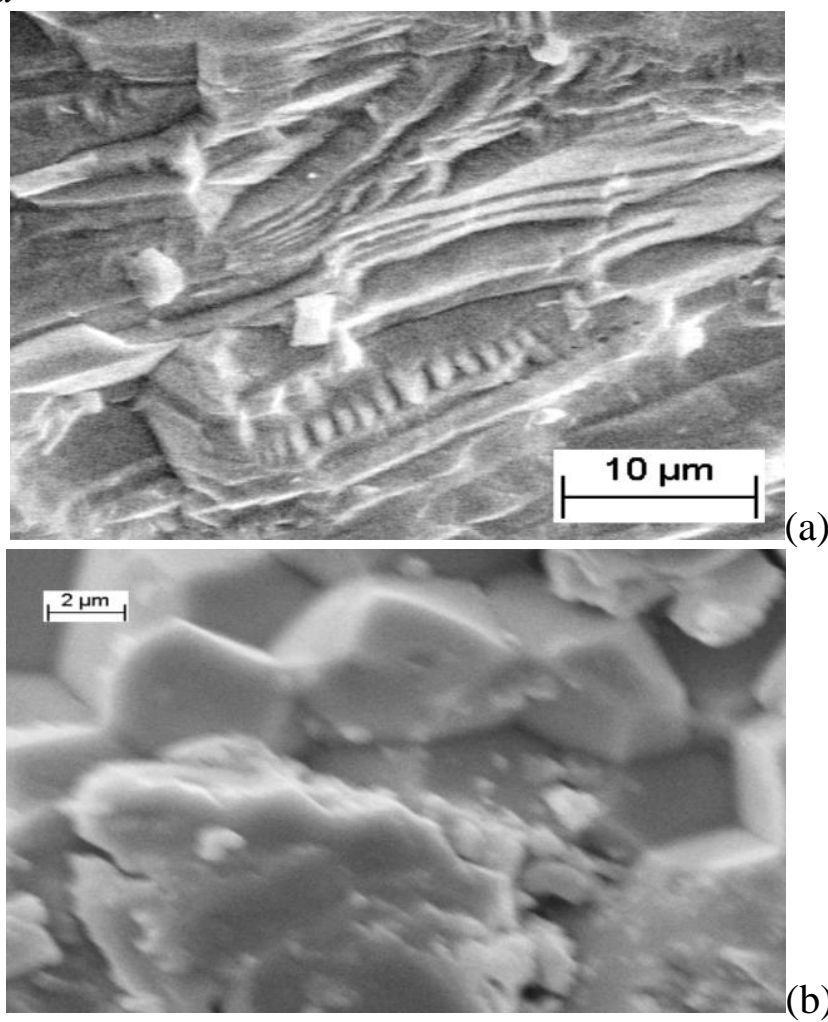

(b) 


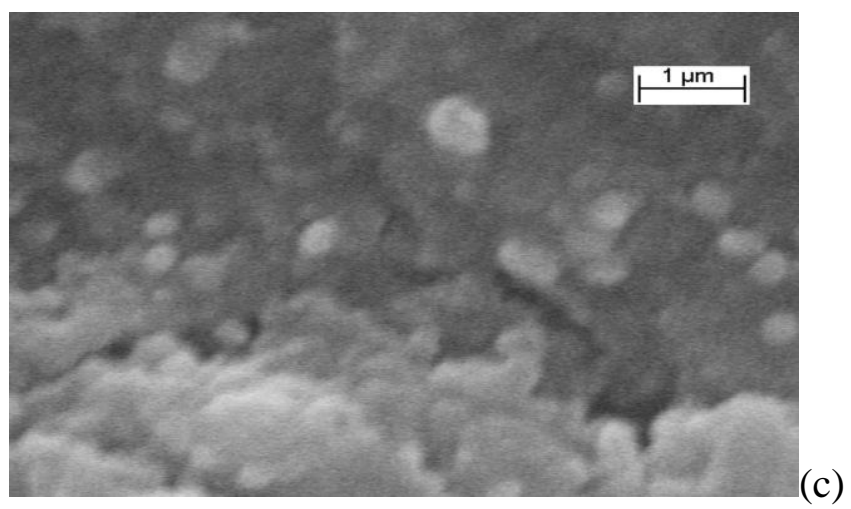

From Fig. 4a (for the ceramics obtained by the SPS method), it follows that the ceramics grains from yttrium oxide are rather well sintered among themselves. According to survey photos of electronic microscopy of this sample, the estimated average size of grains of yttrium oxide created by the SPS method, is less than 5 microns while this size at the traditional method of ceramics preparation was about 10 microns. Respectively, the microhardness of the ceramics from yttrium oxide created by the SPS method was $15.5 \mathrm{GPa}$, against $11 \mathrm{GPa}$ for $\mathrm{Y}_{2} \mathrm{O}_{3}$ ceramics prepared by the traditional method.

When using SPS method, in a sample of ceramics of zinc oxide $\mathrm{ZnO}$ at $\mathrm{T}_{\max }=1500^{\circ} \mathrm{C}$ (Fig. $4 \mathrm{~b}$ ) grains of ceramics had the size of $2-5$ microns, in ceramics of iron oxide $\mathrm{Fe}_{3} \mathrm{O}_{4}$ at $\mathrm{T}_{\max }=800^{\circ} \mathrm{C}-$ about 1 micron and less, and in ceramics of silica $\mathrm{SiO}_{2}$ at $\mathrm{T}_{\max }=1000^{\circ} \mathrm{C}-300 \mathrm{~nm}$ (Fig. 4c).

\section{Conclusions}

Research was carried out on the creation of fine grained ceramics, using the spark plasma sintering (SPS) method, on the basis of various nanodimensional powders of alumina and other oxides.

A comparison of microhardness of the ceramics samples obtained from nanopowders of 14 oxides and from the composites on the basis of alumina nanopowders was carried out.

It is found that at alumina nanopowders using:

1) the microhardness of the ceramics obtained by the method of the spark plasma sintering (SPS) is significantly higher than the microhardness of the ceramics obtained by the traditional method (at consecutive pressing and sintering); at the SPS method the average size of the ceramics grain decreases (to 1 micron and less),

2) the ceramics microhardness strongly depends on the phase structure of initial nanopowder. It increases with change of the powder phase structure in such sequence: (1) $\delta$ - and $\theta$-phases, (2) $\gamma$-phase, (3) $\alpha$-phase, (4) composites on the basis of the $\mathrm{Al}_{2} \mathrm{O}_{3}$ powders of $\alpha$-phase,

3 ) for the ceramics of $\alpha$-phase (corundum), obtained by the same method (either traditional, or SPS), the ceramics microhardness is higher than less the average size of the initial-powder particles, 
4) for the composite samples, with the SPS method, the fine-grained, dense, strong ceramics with microhardness up to $23 \mathrm{GPa}$ is obtained.

From the nanodisperse powders of various oxides (of zinc, iron, copper, chromium, cobalt, tungsten, magnesium, niobium, titan, yttrium, zirconium), the dense and hard ceramics with the fine-grained structure (about 1 micron and less) is obtained with the SPS method.

The microhardness of the ceramics created (from nanopowders of different oxides) with the SPS method, is significantly higher than the microhardness of the ceramics obtained with the traditional method.

\section{References}

Anisimov, A., Bardakhanov, S., Zav'yalov, A., Zobov, K., Lysenko, V., Mali, V., Trufanov, D. (2013). 'Influence of sintering conditions on structure and property of ceramics from nanodimensional silica powders.' Bulletin of NSU. Physics series. 8(1): 107-114. [In Russian].

Antsiferov, V. \& Perelman, V. (2001). Mechanics of processes of pressing of powder and composite materials, 175-202. Moscow. [In Russian].

Bae, C., Bardakhanov, S., Chong, J., Kim, A., Lee, D., Lienko, V., Rustamov, Sh., Sah, J. (2002). 'Ceramic Preparation of Nano- and Micropowder.' Abstracts of the $9^{\text {th }}$ Intern. Symp. on Metastable, Mechanically Alloyed and Nanocrystalline Materials, in Seoul, Korea.

Bardakhanov, S., Lysenko, V., Malov, A., Maslov, N., Nomoev, A. (2008). 'Structure and properties of ceramics on the basis of nanodisperse powders of gadolinium oxide and yttrium oxide.' Physical mesomechanics. 11(5): 111-114. [In Russian].

Bardakhanov, S., Kim, A., Lysenko, V., Maslov, N., Nomoev, A., Rozhin, I. \& Trufanov, D. (2009a). 'Structure and properties of nanoceramics on the basis of alumina powder.' Nanoindustry. 14(2): 22-25. [In Russian].

Bardakhanov, S., Lysenko, V., Nomoev, A., Trufanov, D. (2009b). 'Receiving and properties of nanopowder of tungsten oxide and ceramics from it.' Science and technologies in the industry. (4): 39-41. [In Russian].

Bardakhanov, S., Kim, A., Lysenko, V., Nomoev, A., Trufanov, D., Buyantuev, M., Bazarova, D. (2009c). 'Properties of the ceramics obtained from nanodisperse powders.' Inorganic materials. 45(3): 379-384. [In Russian].

Bardakhanov, S., Emelkin, V., Lysenko, V., Nomoev, A., Trufanov, D. (2009d). 'Obtaining and properties of ceramics from zirconium dioxide nanopowder.' Physics and chemistry of glass. 35(5): 710-714. [In Russian].

Bardakhanov, S., Lysenko, V., Nomoev, A., Trufanov, D., Fokin, A. (2010). 'Ceramics obtaining from nanopowder of copper protoxide and its properties.' Materials science questions. (3): 82-85. [In Russian].

Lysenko, V. (2013). 'Ceramics from nanopowder of zinc oxide. Obtaining, structure, properties.' Nanoindustry. (1): 38-40. [In Russian].

Lysenko, V., Gorev, V., Litvinenko, Yu., Bardakhanov, S. (2013). 'Obtaining and properties of ceramics from nanopowder of iron oxide.' Bulletin of NSU. Physics series. 8(1): 99-103. [In Russian].

Moiseev, I., Klimov, D., Spitsyn, B., Kotov, Yu., Pusanov, A., Mikaelyan, A., Alfimov, M. \& Rakhovskiy, V. (2003). 'Discussion of problems of 
nanotechnology.' Messenger of the Russian Academy of Sciences 73(7): 429-449. [In Russian].

Nanoparticles, Nanostructures \& Nanocomposites (2004). Book of Abstracts of the Topical meeting of the European Ceramics Society, July 5-7, in St. Peterburg, Russia.

Nanostructures: Physics and Technology (2007). Proceedings of $16^{\text {th }}$ International Symposium, June 25-29, in Novosibirsk, Russia

Physicochemistry of ultradisperse systems (Ed. Petrunin, V.) (2000). Theses of the V Russian Conference, October 9-13, in Ekaterinburg, Russia. [In Russian].

Zhou Xinzhang, Hulbert, D., Kuntz, J., Sadangi, R., Shukla, V., Kear, B. \& Mukherjee, A. (2005). 'Superplasticity of zirconia-alumina-spinel nanoceramic composite by spark plasma sintering of plasma sprayed powders.' Materials Science and Engineering A 39: 353-359. 
